\title{
TIMING OF THE LANDSLIDE-DAMMED LAKE TRIGGERED BY EARTHQUAKE, AT TOYAMA RIVER, CENTRAL JAPAN
}

\begin{abstract}
Akiko S Goto $^{1}$ Takeshi Muramatsu² Yoshiji Teraoka² $^{2}$
ABSTRACT. Huge landslides triggered by strong earthquakes or torrential rains can result in unstable natural dams that pose serious risks to humans. In this study, we attempt to document the age of an ancient earthquake that produced a landslidedammed lake. A buried forest found in the Toyama River area of the southern Nagano Prefecture, central Japan, provides evidence of this event. The dammed lake formation has been previously estimated to have occurred in AD 714. However, the age of the dam and the way it was formed have never been directly determined. To determine the position and timing of the landslide dam, we analyzed the radiocarbon content of branches and wood fragments from a brecciated deposit. We show that the ${ }^{14} \mathrm{C}$ dating method is suitable for clarifying the timing of burial for a variety of trees, although the method does not produce a narrow age for the event. In addition to the dating, we determined the landslide dam's position and reconstructed the formation of the lake.
\end{abstract}

\section{INTRODUCTION}

Landslide-dammed lakes are commonly triggered by huge earthquakes or torrential rains, sometimes with disastrous consequences. Many landslide dams have formed and collapsed in Japan due to the combination of the mountainous topography, friable rocks, and numerous streams that flow through steep canyons. Niigata Prefecture (Japan), for example, was damaged in 2004 by landslidedammed lakes triggered by a huge inland earthquake (Sassa 2005). This event submerged houses as well as croplands. Moreover, other landslide-dammed lakes formed by huge earthquakes were reported elsewhere (e.g. Dunning et al. 2007; Wen et al. 2008). An understanding of ancient earthquakes and associated landslide events is important for future disaster planning and mitigation because the earthquakes repeatedly occur along active faults. It is especially important to collect information regarding the timing of the formation and collapse of ancient landslide-dammed lakes caused by earthquakes.

Evidence of a landslide-dammed lake was found on the Toyama River in Nagano Prefecture, central Japan. Using dendrochronology on a buried Japanese cypress, researchers estimated the formation of the lake at AD 714 (Teraoka 2003). Teraoka (2006) suggested the timing of the lake formation corresponded with a huge earthquake in the ancient record. However, previous research was not able to determine the landslide dam's area. In this research, many samples were excavated from the landslide avalanche deposit or from lake sediments, and others were sampled from buried trees exposed along a streambed. We applied the ${ }^{14} \mathrm{C}$ dating method to date the dam formation in this case because the samples consisted of mixed species with an insufficient number of rings for use in dendrochronology. In this report, we determine the area of the landslide dam associated with the AD 714 earthquake by determining its age from buried wood fragments inside a brecciated deposit. From these results, we discuss the origin and aspect of the landslide-dammed lake on the Toyama River.

\section{FIELD OUTLINE AND SURVEY}

The Toyama River winds through a mountainous area in the southern part of Nagano Prefecture, Japan (Figure 1). Recently, dam construction has reduced its flow, causing many trees that had been buried along the riverbanks to be exposed. Evidence of landslide-dammed lakes includes landslide

\footnotetext{
${ }^{1}$ Center for Chronological Research, Nagoya University, Furo-cyo, Chikusa-ku, Nagoya, Aichi 464-8602, Japan. Present address: Department of Chemistry, Tokyo Metropolitan University, 1-1 Minami-Osawa, Hachioji, Tokyo 192-0397, Japan. Corresponding author. Email: akigoto@tmu.ac.jp.

${ }_{2}^{2}$ Iida City Museum, 2-655-7 Oute-machi, Iida, Nagano 395-0034, Japan.
}

(C) 2010 by the Arizona Board of Regents on behalf of the University of Arizona Proceedings of the 20th International Radiocarbon Conference, edited by A J T Jull RADIOCARBON, Vol 52, Nr 2-3, 2010, p 1090-1097 
avalanche deposits and buried trees (Muramatsu 2006). Outcrops of lake sediments show that the dam remained for a long period. The Ikeguchi River flows into the Toyama River midway between Oshima and Shippeijima, and evidence of a large landslide (Ikebara-kuzure) is observed on the northern flanks of Mt Hikage. Chigira (2002) reported the volume of this deposit to be about $93,750,000 \mathrm{~m}^{3}$.

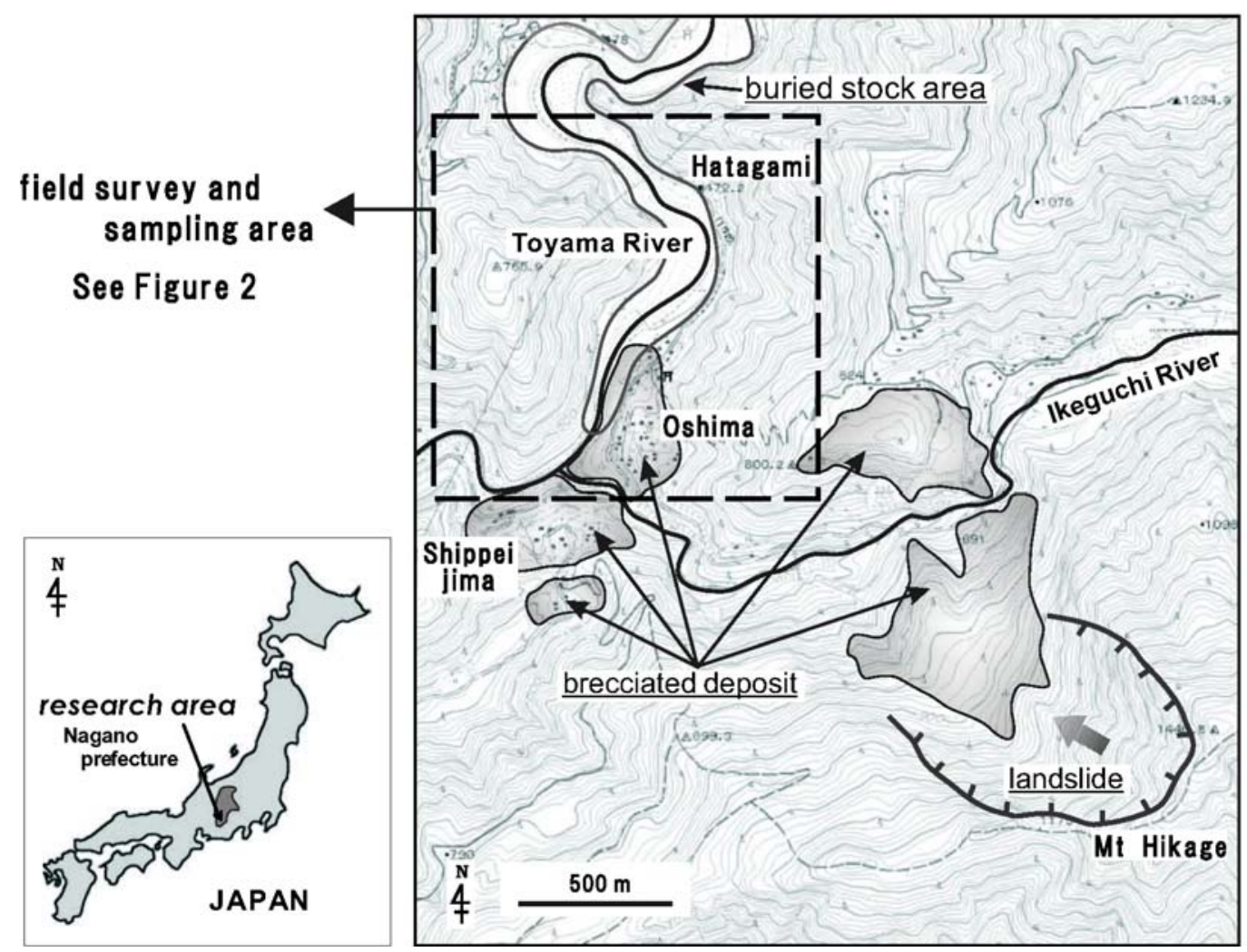

Figure 1 Location and map of the research area. Based on the 1/25,000 scale topographic maps supervised by Geographical Survey Institute, "Inawada” and "Kamimachi.”

We found large boulders, each $\sim 2 \mathrm{~m}$ in diameter, on opposite hillsides flanking the Ikeguchi River where it meets the Toyama River. These indicate the maximum height of the landslide avalanche, which is $\sim 50 \mathrm{~m}$ above the present streambed of the Toyama River. Results of our geological survey suggest that the brecciated deposit dammed up the Toyama River, and its form was an alluvial cone that stretched from Oshima to Shippeijima (Figure 1). We suggest that the material for this deposit was derived from Mt Hikage, based on rock type, flow direction, and volume.

The lake sediments form 2 different types of deposits, including those with distinct horizontal layering, and those with haphazard blocks of clay with bend layers, especially notable around Hatagami, where roof tiles were fabricated in historical times. The lake sediment of the former type consists of clay and silt layers, $>6 \mathrm{~m}$ in height and sometimes with varve-like laminae. This deposit overlies river gravel, including numerous rounded stones up to several $\mathrm{cm}$ across. We suggest that the dammed lake must have lasted for some time, in order to produce the laminated layers seen in the outcrop. We interpret the clay blocks as allochthonous material torn from the original outcrop. 


\section{SAMPLE DESCRIPTION}

Figure 2 shows the locations of sampling sites and their stratifications. Samples are classified as Type I, II, or III, according to their depositional environments as shown in Figure 3. Types I and II samples were associated with the landslide avalanche and/or debris flow deposits. Type I samples were contained in the brecciated deposit around Oshima, and Type II samples were taken from buried trees in growth position along the streams, formerly covered by the brecciated deposit. Type III samples are from the lake sediment upstream from Hatagami. These were deposited at the bottom of the landslide-dammed lake. We give a detailed description and sampling conditions for these 3 sample types in the following section.

\section{a)}

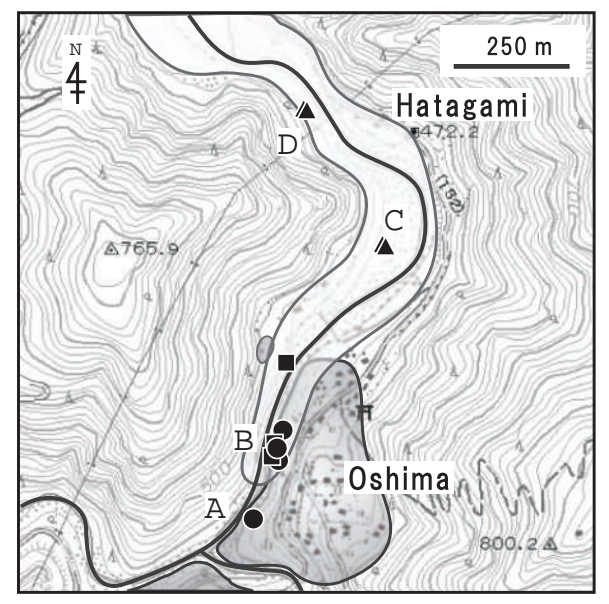

NOTE b)

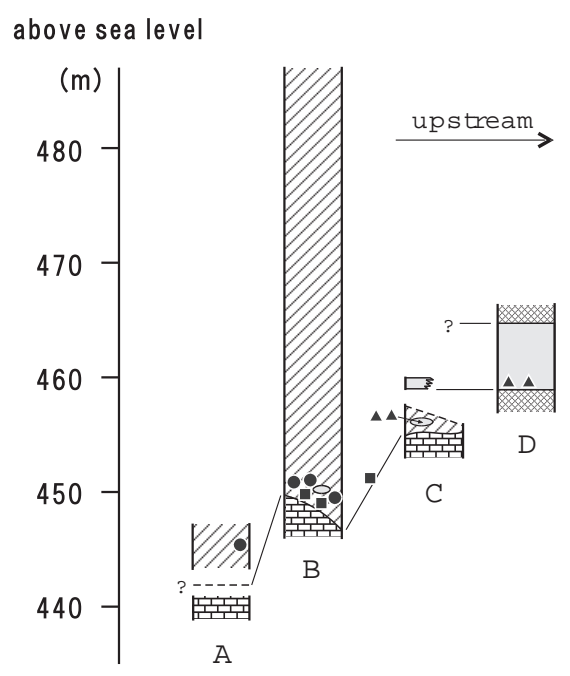

Figure 2 Sampling sites and their stratifications: a) Location of the sampling sites. Based on the 1/25,000 scale topographic map ("Inawada”) supervised by Geographical Survey Institute; b) Stratifications of each sampling site.

\section{Type I (Os-SA01, Os-SA05, Os-SA08, Os-SA11)}

Type I samples were collected on the east side of the Toyama River near Oshima. Os-SA01 is a buried chip preserved under different conditions than the other 3 samples in this group, and was found slightly downstream from them. It is moderately well preserved; small stones $(<2 \mathrm{~cm})$ are cemented to the sample by sand and silt, with no large stones.

Os-SA05, Os-SA08, and Os-SA11 were collected from nearby places as a series in the brecciated deposit in which many large cobbles (>10 cm diameter) were present. Os-SA05 is from a Japanese cypress (20 cm diameter), which jutted out from a cliff. The upstream side of the sample was worn by flood water, but we were able to collect samples in good condition from the outer tree rings for 

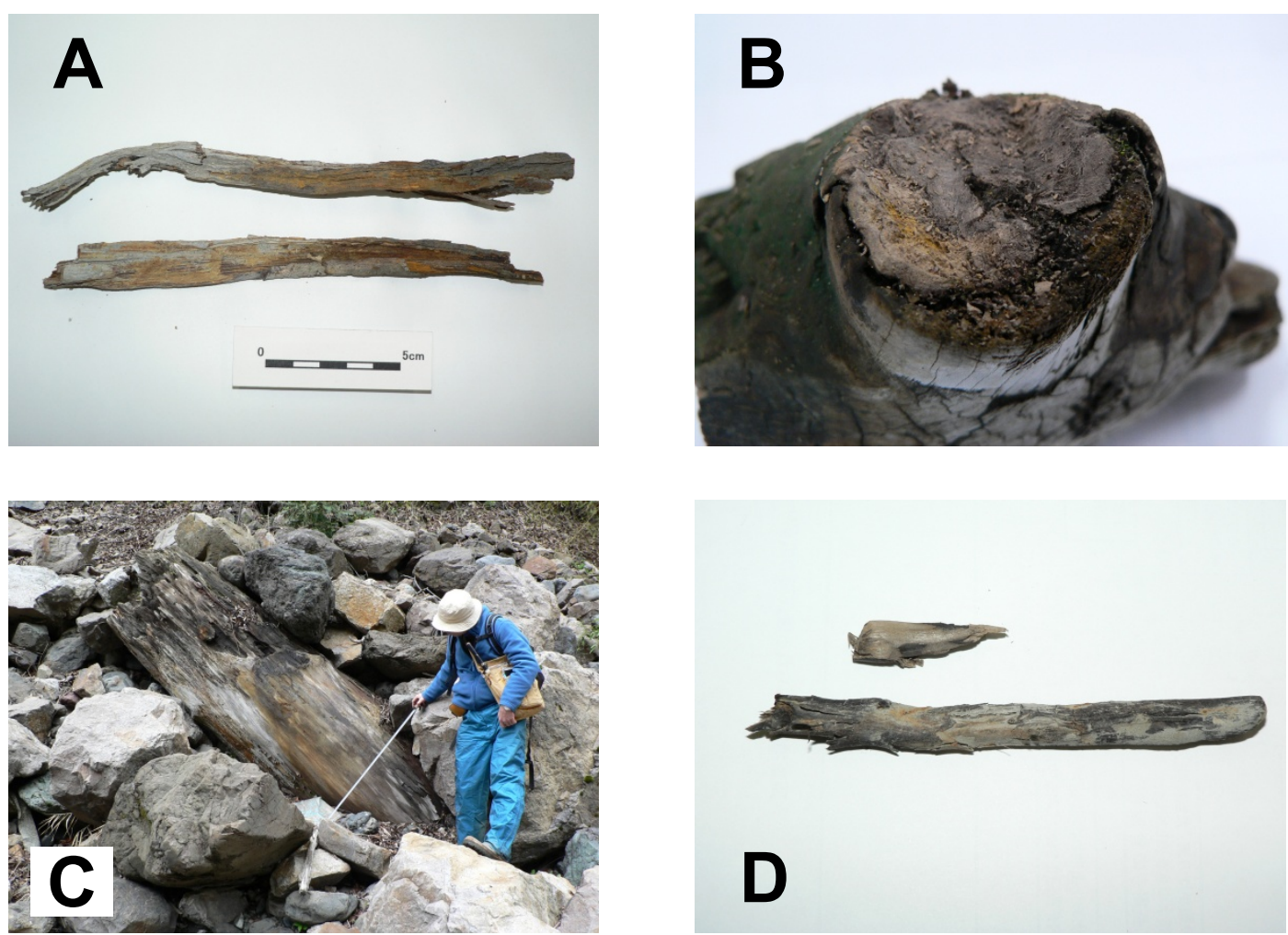

Figure 3 Photographs of collected sample for the ${ }^{14} \mathrm{C}$ dating. A) Os-SA08: Type I, branch from rock avalanche deposit (scale $5 \mathrm{~cm}$ ); B) Os-SA10: Type II, callus of buried stock $\sim 3 \mathrm{~cm}$ diameter; C) Os-SA13-2: Type II, buried stock ( $90 \mathrm{~cm}$ diameter) with bark at streamside; D) Os-SA14-1: Type III, branch from clay layer. It was carbonized and $<2 \mathrm{~cm}$ thick.

dating. Os-SA08 (Figure 3A) was found only a few meters upstream from Os-SA05. The surface of Os-SA08 was not well preserved, so its core was used for dating. We assumed that the time difference between the core and outer rings is within analytical errors as it was only a couple of cm across. Os-SA11 was a branch about $4 \mathrm{~cm}$ in diameter that kept its original shape. We collected the freshest samples from outside tree rings.

\section{Type II (Os-SA06, Os-SA10, Os-SA13-2)}

Os-SA06 and Os-SA10 (Figure 3B) are from buried stumps that stood beside the stream, between the river and the brecciated deposit outcrop. Many buried stumps were found in the same vicinity, covered by the same landslide avalanche and/or debris flow deposit. The diameter of Os-SA06 is approximately $1 \mathrm{~m}$, but it has been eroded by water flow. The Os-SA06 sample for dating was cut from its existing outer rings. Sample Os-SA10, collected a few meters upstream from Os-SA06, is an important key for estimating the timing of the damming event. A thin callus, which probably grew just prior to the burial event, was preserved on Os-SA10 and covered a broken branch $(\sim 3 \mathrm{~cm}$ diameter). We used the callus for direct determination of the timing of the dam formation because the tree was buried under the deposit at the same time the callus grew.

Os-SA13-2 ( 90 cm diameter; Figure 3C) is a well-preserved Japanese cedar with tree bark. This sample was located $\sim 200 \mathrm{~m}$ upstream from Os-SA06 and Os-SA10. It was scarcely damaged by the 
brecciated deposit yet died buried at the lake bottom. We carefully selected the sample for dating and collected the inside tree rings, about $20 \mathrm{yr}$ from the cambium ring.

\section{Type III (Os-SA14-1, Os-SA14-2, Os-SA15-B, Os-SA15-C)}

Os-SA14-1 and 14-2 had been buried in clay blocks that were damaged by significant stresses as seen in the folded layers between Oshima and Hatagami. These samples may have been repositioned. Several clay blocks of similar origin were observed in the vicinity. Os-SA14-1 (Figure 3D) is a carbonized branch $<2 \mathrm{~cm}$ thick and well preserved for the purpose of radiocarbon dating. Another sample (Os-SA14-2) is a flat carbonized piece of wood.

Two wood fragment samples, Os-SA15-B and 15-C, were taken from the bottom of the lake sediment outcrop, near the boundary between clay and river gravel at Hatagami. The inside of this outcrop was apparently preserved under reducing conditions, as a rapid color change occurred when we exposed the material to air when collecting the sample for dating. Os-SA15-B and 15-C were well preserved without heavy weathering, although the original position of the trees these samples came from could not be determined.

\section{${ }^{14} \mathrm{C}$ DATING RESULTS}

All samples were cut and flushed with distilled water, and subsequently treated with $\mathrm{HCl}$ and $\mathrm{NaOH}$ to remove foreign matter. The samples were combusted to $\mathrm{CO}_{2}$ and the purified $\mathrm{CO}_{2}$ gas was reduced to graphite. We analyzed the ${ }^{14} \mathrm{C}$ content of the samples with the HVEE Tandetron accelerator mass spectrometer at the Center for Chronological Research, Nagoya University. Dates are calibrated using the OxCal v 4.0.3 program (Bronk Ramsey 1995, 2001) and the IntCal04 data set (Reimer et al. 2004).

Dating results are shown in Table 1 and Figure 4. The dates of the 3 branches and the tree chip (Type I) were within cal AD 573-852, although both were collected from different types of deposits. We expect that the age for Os-SA08 is consistent with the burial event because the loss of its outer rings was very small. The 2- $\sigma$ calibrated ages for Os-SA08 are cal AD 660-783, 789-810, 849-852. The result for sample Os-SA11 was more tightly constrained, as the existing outermost ring was closer to the cambium. The calibrated date of Os-SA11 was cal AD 596-679 (2 $\sigma)$.

Table 1 AMS ${ }^{14} \mathrm{C}$ dates of wood fragments around the Toyama River. Data calibrated using OxCal v 4.0.3 (Bronk Ramsey 1995, 2001) and the IntCal04 calibration curve (Reimer et al. 2004).

\begin{tabular}{llllll}
\hline $\begin{array}{l}\text { Sample } \\
\text { name }\end{array}$ & $\begin{array}{l}\text { Sample } \\
\text { type }\end{array}$ & Description & $\begin{array}{l}\text { Lab code } \\
\text { (NUTA2-) }\end{array}$ & $\begin{array}{l}{ }^{14} \mathrm{C} \text { age } \\
(\mathrm{BP})\end{array}$ & $\begin{array}{l}\text { Calibrated date }(2 \sigma) \\
(\text { cal AD) }\end{array}$ \\
\hline Os-SA01 & Type I & Wood fragment & 11341 & $1305 \pm 33$ & $657-773$ \\
Os-SA05 & Type I & Thick branch & 11347 & $1424 \pm 33$ & $573-660$ \\
Os-SA08 & Type I & Branch & 11350 & $1278 \pm 33$ & $660-783,789-810,849-852$ \\
Os-SA11 & Type I & Branch & 11343 & $1392 \pm 33$ & $596-679$ \\
Os-SA06 & Type II & Buried stock & 11344 & $1576 \pm 33$ & $415-555$ \\
Os-SA10 & Type II & Callus & 11348 & $1281 \pm 33$ & $658-782,790-809$ \\
Os-SA13-2 & Type II & Buried stock & 11349 & $1303 \pm 33$ & $658-773$ \\
Os-SA14-1 & Type III & Branch & 11359 & $1447 \pm 34$ & $556-654$ \\
Os-SA14-2 & Type III & Wood fragment & 11360 & $1638 \pm 33$ & $337-535$ \\
Os-SA15-B & Type III & Wood fragment & 11352 & $1333 \pm 33$ & $645-724,739-771$ \\
Os-SA15-C & Type III & Wood fragment & 11353 & $1423 \pm 55$ & $467-481,534-690,751-762$ \\
\hline
\end{tabular}




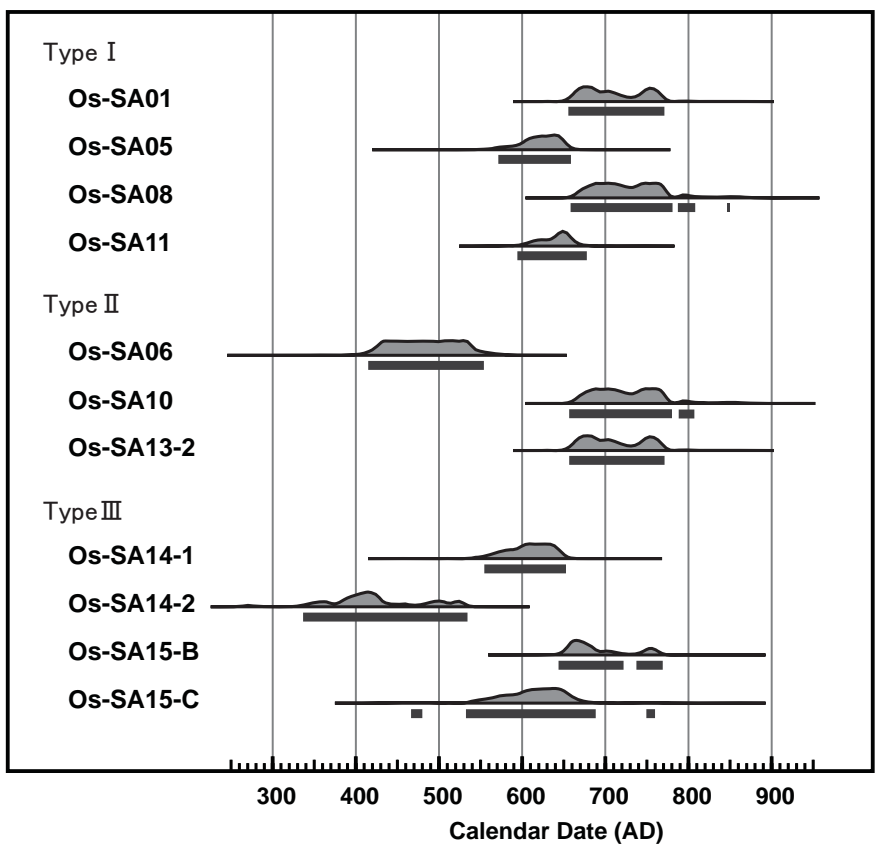

Figure 4 Probability distributions of age ranges of wood fragments from around the Toyama River (using OxCal v 4.0.3., Bronk Ramsey 1995, 2001). Lines below each distribution show $2-\sigma$ confidence for these distributions.

The timing of the dammed lake formation was determined from the dates of Os-SA06 (cal AD 415-

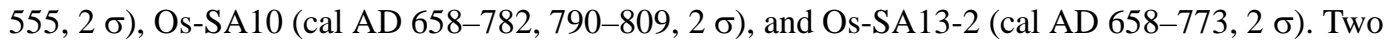
samples are from the same area, yet the calibrated age of Os-SA14-2 was statistically older than that of Os-SA14-1. The former (wood chip) showed cal AD 337-535 (2 $\sigma)$ and the latter (branch) was cal AD 556-654 (2 $\sigma)$. Dates for Os-SA15-B and 15-C, from the preserved lake sediments, range from cal AD 470 to $770(2 \sigma)$.

\section{DISCUSSION}

\section{When Did the Landslide that Formed the Dammed Lake Happen?}

The ${ }^{14} \mathrm{C}$ ages of the samples covered by the brecciated deposit around the stream gave an age of between cal AD 415 and 852, in association with the landslide. One branch sample (Os-SA08) from the breccia and the buried stump samples (Os-SA10, Os-SA13-2) provide very reliable results because their sedimentological context suggests instantaneous burial and their preservation was excellent. We use all 3 samples to refine our age estimate of the landslide and dam formation between cal AD 660-770.

This age range is consistent with the dendrochronological age estimate of AD 714 based on the time of death of a Japanese cypress collected from Hatagami (Teraoka 2003). Previous research also substantiates this age, as historical documents record a large earthquake in AD 714 at Totomi-Jishin (Teraoka 2006). The timing of the landslide, as estimated from branches and tree stumps excavated from under the brecciated deposit, is also consistent with the age of this earthquake. An ancient document describes huge landslides in the area of the Tenryu River, into which the Toyama River flows $\sim 10 \mathrm{~km}$ downstream from the research area. The distribution and direction of the landslide ava- 
lanche suggests that the avalanche slid down to the Ikeguchi River and Toyama River from Mt Hikage (Chigira 2002). We can confirm the collapse on the northern slope of the mountain. The brecciated deposit remaining on the hillside implies that it formed a dam that was over $50 \mathrm{~m}$ height as compared to the present streambed, and the dammed lake extended $3 \mathrm{~km}$ upstream. Therefore, we determined that the brecciated deposit found in our survey was triggered by the huge earthquake that occurred in AD 714, which caused a natural dam to form from the Oshima to Shippeijima area, and subsequently the forest around the Toyama River was immersed to the lake bottom.

In the previous research, age estimations were made for each of the other 7 Japanese cypresses' outermost layers, with no surviving cambium layer, and they were uniformly older than AD 710. We require more information, such as species and/or growth conditions, to use the method of dendrochronology. However, it was very difficult to find suitable samples, especially from the brecciated deposit, because they were crushed and subsequently subjected to extreme dry or humid conditions. Therefore, we believe that the ${ }^{14} \mathrm{C}$ dating method provides the best available age estimate, although it cannot provide an exact date.

\section{Was the Landslide-Dammed Lake Formed Repeatedly?}

Although we found that the formation of the dam and lake was consistent with the huge earthquake of $\mathrm{AD} 714$, we cannot at this time say that this was a unique event. Three samples (Os-SA05, OsSA06, and Os-SA11) from the area buried by the brecciated deposit of AD 714 apparently were not killed by this event. The dates of these 3 samples were older than AD 714. Os-SA05 and Os-SA11 were branches collected from the brecciated deposit, and each sample showed thick and worn branches that were not suitable for the purpose of calculating precise ages. These samples reflected different timing, which could be related to a more complicated history. This history, with the overprint of repeated earthquakes, is not completely clear.

Os-SA14-1 was dug up from a clay block and dated to a period 50 yr older than AD 714. We consider this estimate to be significant because the sample was a well-preserved narrow branch. The clay blocks included wood fragments distributed between Oshima and Hatagami, and some of the separated clay blocks, which were dozens of $\mathrm{cm}$ thick, were folded by pressure from the brecciated deposit associated with AD 714 event. This suggests that the clay accumulated in an earlier lake and became consolidated into the AD 714 landslide debris deposit. We expect that several landslides probably occurred in the same area repeatedly. To fully understand this history, however, would require additional sedimentological evidence from a geological and geographical survey, as well as a larger number of sound ${ }^{14} \mathrm{C}$ dates on the blocks.

\section{CONCLUSION}

We clarified the history of the landslide-dammed lake associated with a AD 714 earthquake in the Toyama River area of the southern Nagano Prefecture, central Japan. The landslide dam resulted from a landslide avalanche and/or debris flow deposit from the direction of Mt Hikage, according to our geological survey data. The dam was formed along the Toyama River primarily around Oshima and Shippeijima. We suggest that many trees that had stood on the slope of the mountainside and riverbank were incorporated into a brecciated debris deposit. In the context of this interpretation, the timing of the landslide dam formation was estimated using ${ }^{14} \mathrm{C}$ dating. The estimated period when the landslide and its dam occurred is consistent with the age determined in previous studies, at AD 714. The landslide-dammed lake extended $3 \mathrm{~km}$ upstream from the site of the dam. 
It is difficult to make conclusions about previous landslide-dammed lakes in the study area because we need more information from well-preserved samples, but consideration of the 3 sample types identified here suggests the possibility of recurrent landslide events. This effort is hampered by the destructive nature of the most recent landslide dam and river erosion at the Toyama River site. However, at present we note the possibility of repeated landslide dam formation in the study area, based on a distinct time gap in ${ }^{14} \mathrm{C}$ ages determined from material contained in the debris flow, and on the geological information about the brecciated deposits and associated clay sediments. For determination of this question, we must conduct more detailed geological and geographical research, along with the dating of these formations.

\section{ACKNOWLEDGMENTS}

We acknowledge Dr Toshio Nakamura (Nagoya University) for his excellent support during the ${ }^{14} \mathrm{C}$ analysis, and Ms Akiko Ikeda (Nagoya University) for her assistance with sample preparation. We also thank Drs Kazuhiro Suzuki and Takenori Kato (Nagoya University) for useful discussions and advice about our article. Two anonymous reviewers provided helpful comments and assistance with the manuscript. This research was supported by "Grants-in-Aid for Scientific Research" (The 21st Century Center of Excellence Program: Nagoya University 2003-2008) from the Ministry of Education, Culture, Sports, Science and Technology.

\section{REFERENCES}

Bronk Ramsey C. 1995. Radiocarbon calibration and analysis of stratigraphy: the OxCal program. Radiocarbon 37(2):425-30.

Bronk Ramsey C. 2001. Development of the radiocarbon calibration program. Radiocarbon 43(2A):355-63.

Chigira M. 2002. Geological structure of the Ikeguchi landslide in southern Alps [abstract]. 41st Annual Meeting of the Japan Landslide Society. p 113-4. In Japanese.

Dunning SA, Mitchell WA, Rosser NJ, Petley DN. 2007. The Hattian Bala rock avalanche and associated landslides triggered by the Kashmir Earthquake of 8 October 2005. Engineering Geology 93(3-4):130-44.

Muramatsu T, editor. 2006. Buried Forests of the Toyama River-A Caution to People from the Ancient Natural Hazard. Minami-Shinano Autonomy Promotion Center and Iida City Museum. 32 p. In Japanese.

Reimer PJ, Baillie MGL, Bard E, Bayliss A, Beck JW, Bertrand CJH, Blackwell PG, Buck CE, Burr GS, Cutler KB, Damon PE, Edwards RL, Fairbanks RG,
Friedrich M, Guilderson TP, Hogg AG, Hughen KA, Kromer B, McCormac G, Manning S, Bronk Ramsey C, Reimer RW, Remmele S, Southon JR, Stuiver M, Talamo S, Taylor FW, van der Plicht J, Weyhenmeyer CE. 2004. IntCal04 terrestrial radiocarbon age calibration, 0-26 cal kyr BP. Radiocarbon 46(3):1029-58.

Sassa K. 2005. Landslide disasters triggered by the 2004 Mid-Niigata Prefecture earthquake in Japan. Landslides 2(2):135-42.

Teraoka Y. 2003. A sequel to the inspection of buried forest along the Toyama River. Ina 51(8):19-25. In Japanese.

Teraoka Y. 2006. Relation between Toyama earthquake and buried forest. Ina 54(6):11-4. In Japanese.

Wen X, Ma S, Xu X, He Y. 2008. Historical pattern and behavior of earthquake ruptures along the eastern boundary of the Sichuan-Yunnan faulted-block, southwestern China. Physics of the Earth and Planetary Interiors 168(1-2):16-36. 